
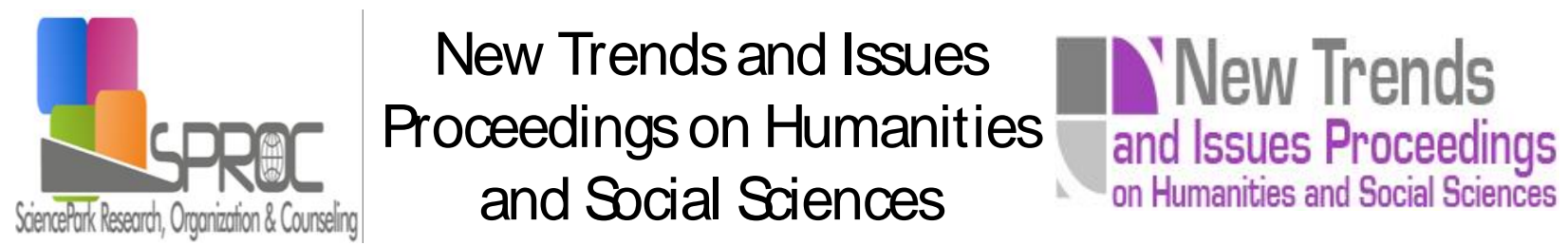

\title{
Learning styles of adults and metacognitive approach to E-Learning "... Towards a cognitive and social constructivist view of learning"
}

Bassiri Mustapha $^{\mathrm{a}^{*}}$

Said Belaaouad ${ }^{\text {b }}$ Laboratory of physical chemistry of Materials,

Radid Mohamed c Laboratory of physical chemistry of Materials,

Suggested Citation:

Humanities and Social Sciences.

New Trends and Issues Proceedings on

Abstract 
New Trends and Issues Proceedings on Humanities and Social Sciences.

1. Introduction

2. The literature review 
New Trends and Issues Proceedings on Humanities and Social Sciences.

3. Methodology 
Table 1. The recommended grid analysis: Anderson and Krathwohl "High Cognitive Learning" Bloom Taxonomy revisited

\begin{tabular}{ccc}
\hline $\begin{array}{c}\text { The knowledge } \\
\text { dimension }\end{array}$ & Remember $d^{\text {Understan Apply }} e^{\text {Analys Evaluate Create }}$ \\
\hline
\end{tabular}

Table 2. Questionnaire semi headed: identifying learning styles semi headed: identification of learning styles 
Questionnaire 2. Quantitative data The ISALEM-97 Questionnaire
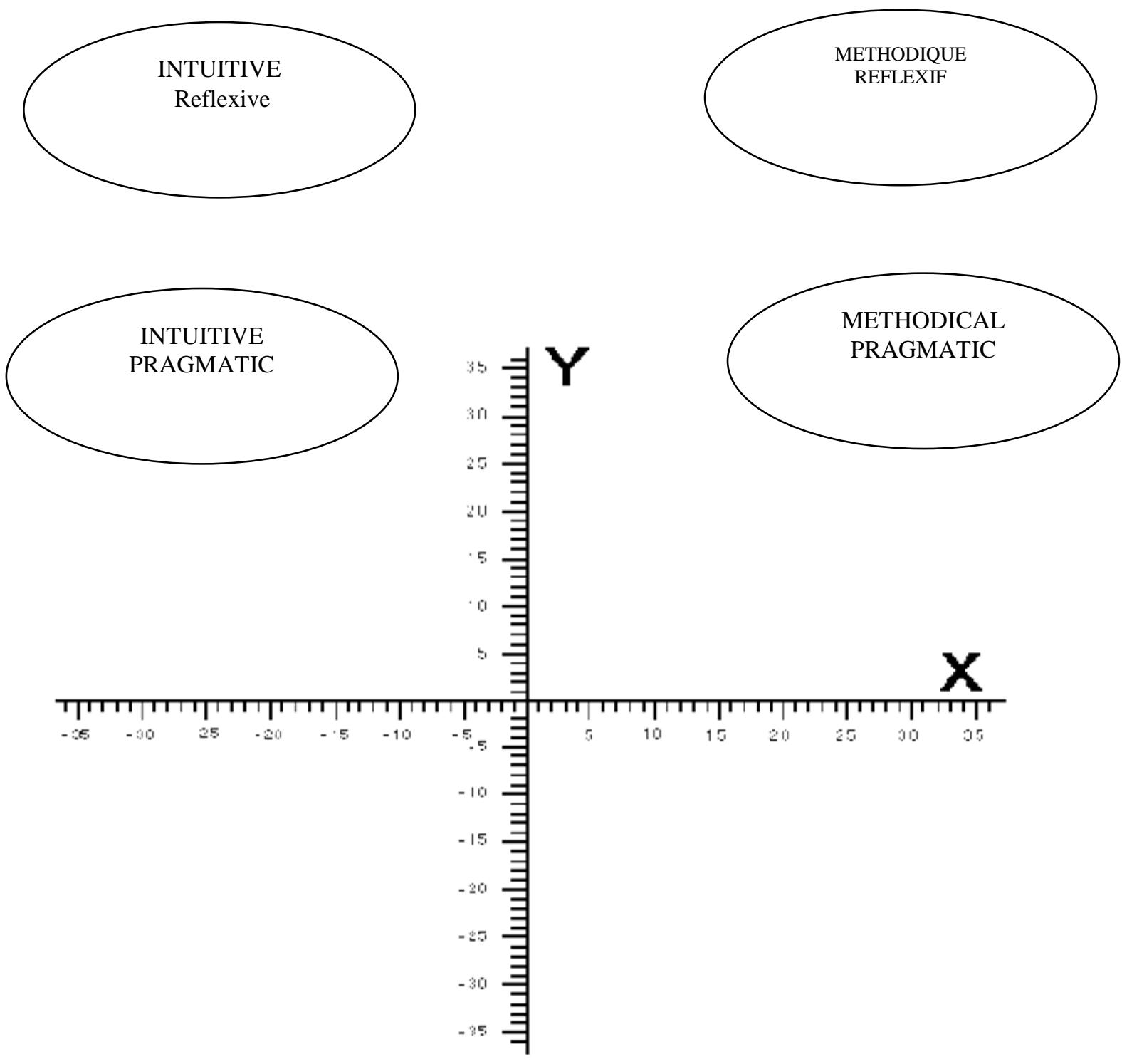
New Trends and Issues Proceedings on Humanities and Social Sciences.

4. Conclusion 
Schematics SYHNTESE TRAINING ENGINEERING TRAINING AD ADULT ONLINE ENLIGNEULTE
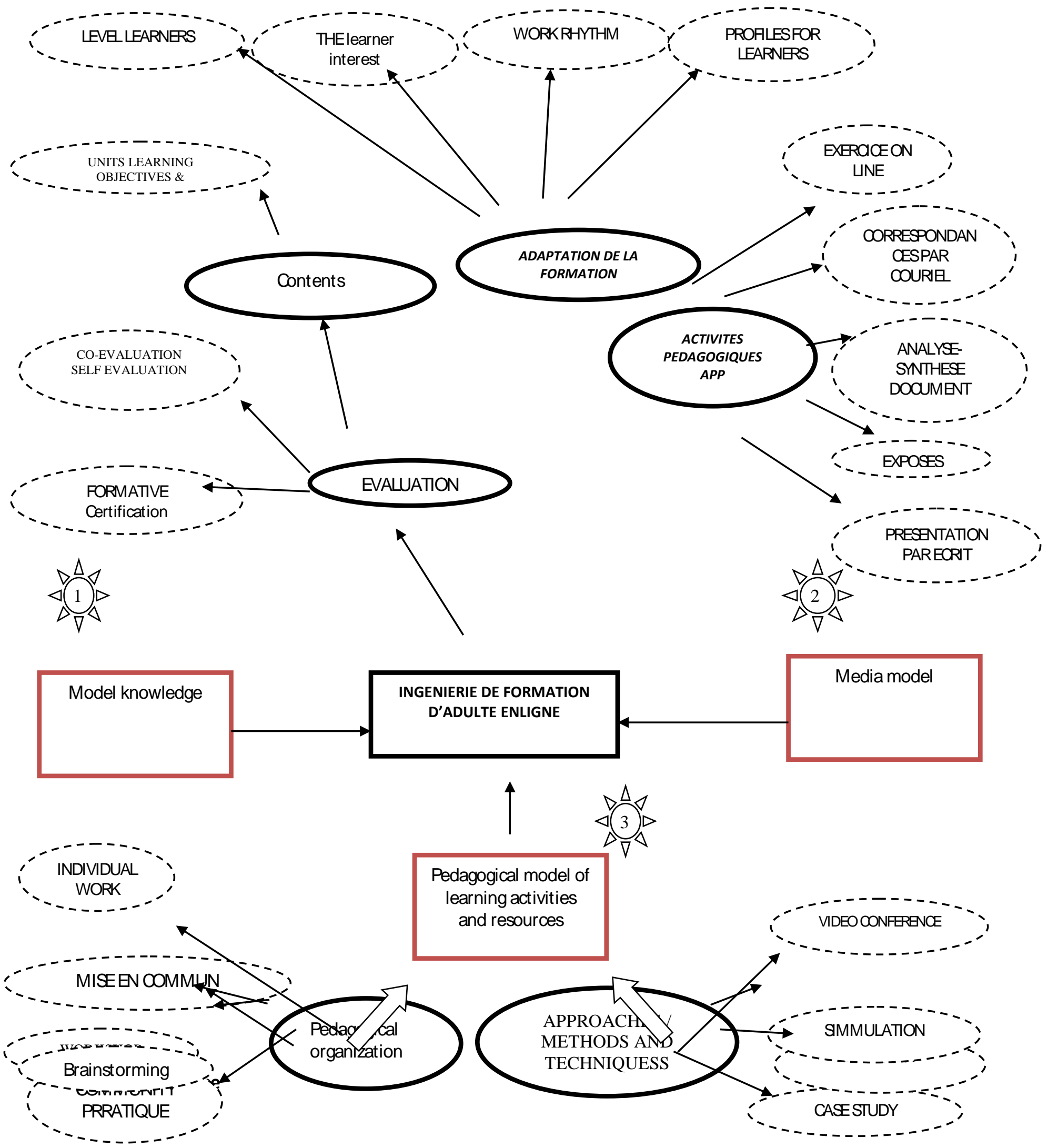


\section{References}

Understanding the new version of Bloom's Taxonomy a brief discussion of the revisions to Bloom's classic cognitive taxonomy by Anderson and Krathwohl and how to use them effectively

The science education

Taxonomy of educational objectives, Volume 1 cognitive domain

BÜCHEL Learning Style and metacognitive theory: A comparison of theoretical concepts and didactic implementation

Multimedia design methodology

The modern practice of adult education. From pedagogy to andragogy

The learning style inventory: Self, Corin inventory and interpretation booklet

Symposium of the French Ergonomics Corporation (SELF)

Cyberspace Open and Training - Towards a mutation training practices?

The changing landscape of languages

International Symposium on Information Technologies in Education: Problems and Perspectives of Research Sharp Questions

Research in professional didactics

Continuing Education, 139

Instructional Strategies CDTL, 5

Self-directed learning: Psychological and educational aspects

As a source of self-regulation 